Murmurations:

Journal of

Transformative

Systemic

Practice

\section{Siobhan Potter}

\section{Volume 3}

\section{Issue 1}

Autumn 2020

\section{Keywords:}

Silence, Covid-19, coronavirus, poetry, pandemic

\section{Citation Link}

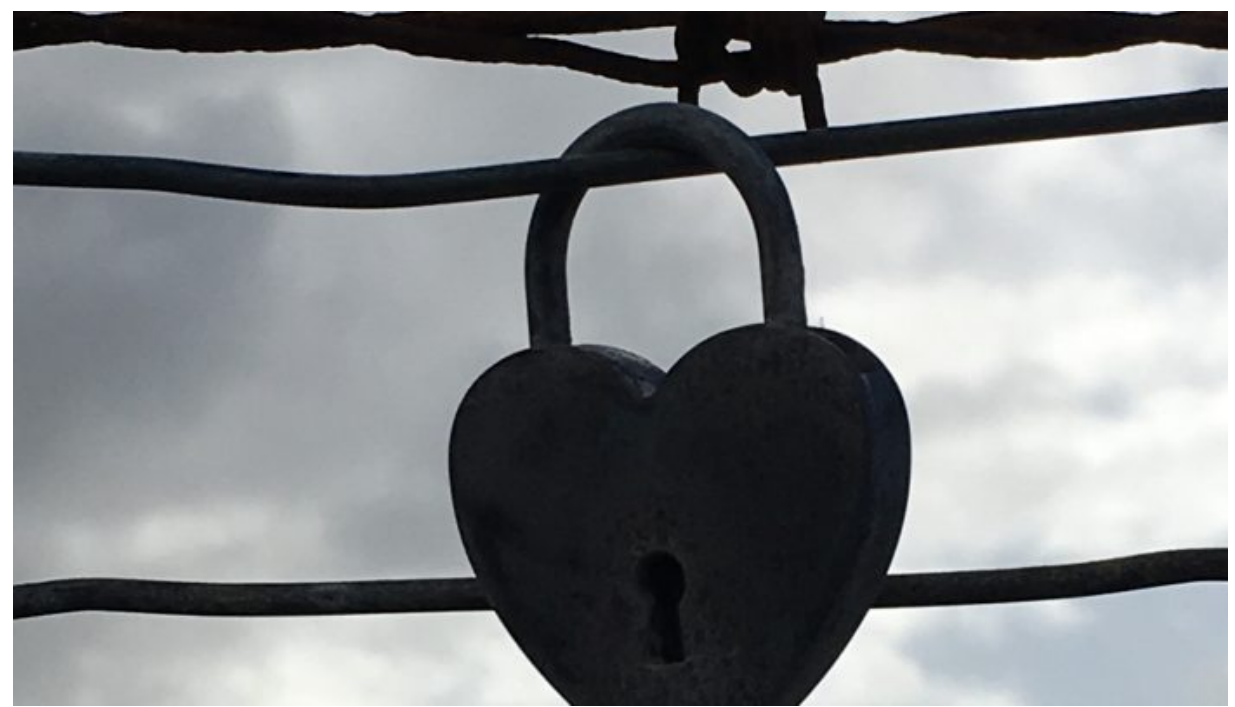

...Poetry lacks the capacity to be cavalier and pass by It's a drive by, connected to landscape in service to its collision potential The drive by shooting of the pandemic cyclist His spit weaponised, collides with bludgeon a word I never utter But I saw this and I thought of you and not in a postcard kind of way Distance tries to happen, passing by What if someday I stopped In Frost'n it, would we collide less Would it make any difference

Or matter

does any of it is any of it matter You stopping To be seduced by green tea and bare feet in the garden, to return Via haiku. And now 


\author{
still passing \\ feeling the passing \\ I pass... \\ 'not the time to be silent' \\ https://www.facebook.com/groups/NotTheTimeToBeSilent/
}

\title{
Citation
}

Potter, Siobhan (2020). .... . Murmurations: Journal of Transformative Systemic Practice, 3, 1, 18-19. https://doi.org/10.28963/3.1.7 